\title{
Comparative Anatomical Study for the Cultivars of Morus L. Species cultivated in North of Iraq
}

\author{
Raad H. M. Al-Badrany ${ }^{1 *}$, Amer M. M. Al-Ma'thidy ${ }^{2}$ \\ ${ }^{1,2}$ Department of Biology, College of Education for Pure Science, University of Mosul, Mosul, Iraq \\ E-mail: ${ }^{1 *}$ raadhamad42@gmail.com, ${ }^{2}$ dr.amer.1956@yahoo.com
}

(Received May 31, 2020; Accepted July 05, 2020; Available online September 01, 2020)

DOI: 10.33899/edusj.2020.127117.1075, (C) 2020, College of Education for Pure Science, University of Mosul.

This is an open access article under the CC BY 4.0 license (http://creativecommons.org/licenses/by/4.0/).

\begin{abstract}
:
The current study involved a comparative anatomical study for the cultivars belonging to the species Morus L. cultivated in north of Iraq that included 14 cultivars of 6 species: M. alba L. ('Beautiful Day', 'Big White', 'Rease', 'Greece', 'Pearl', 'Border Sweet' and 'Pendula'); M. latifolia Poir ('Kokuso Korean'); M. rubra L. ('Amarah'); M. nigra L. ('Shami'); M. macroura Miq ('King White'); 'Dwarf' and M. hybrid ('Tice' and 'Wellington').

The anatomical study included (blade leaf, midrib and venation system) in addition to nonliving components (crystals) in the mesophyll of the blade leaf. The result of the anatomical characteristics of (blade thickness, cuticle, epidermis cell, thickness and layers of palisade and spongy tissue, thickness and shape of arc vascular curve, number and dimension of vessles in the midrib and the shape of idioblast in cystolith). In addition to the venation system of the leaf which found the Brochidodromous type in all cultivars excepted 'BigWhite' and 'Pendula' cultivars of species M. alba and 'Kokuso Korean' cultivars of species M. latifolia founded from Craspedromous type.
\end{abstract}

Certainly they have importance taxonomic value in the separation and identification among the cultivars of the species studied belong to the genus Morus L.

Keyword: Anatomical Study, Cultivars, Morus, North of Iraq

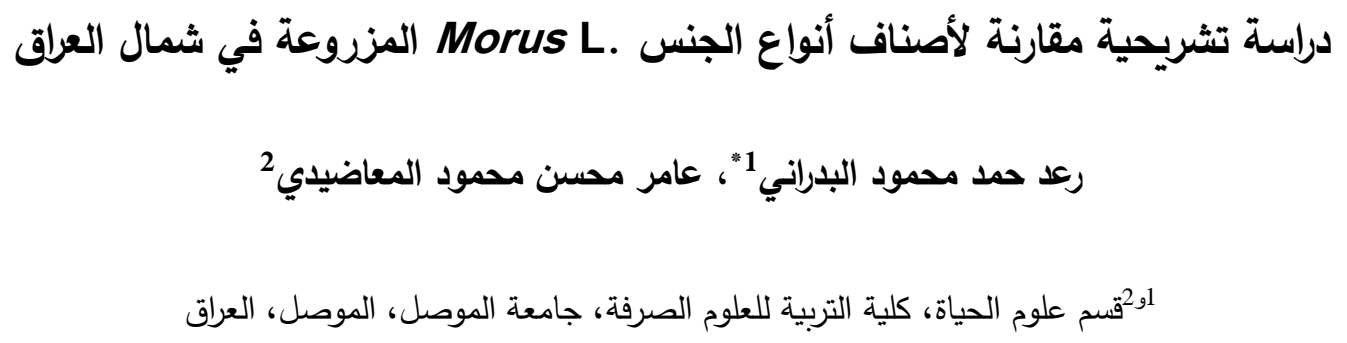

تضمن البحث الحالي دراسة تشريحية مقارنة لاصناف انواع الجنس Morus L. المزروعة في شمال العراق والتي تضمنت

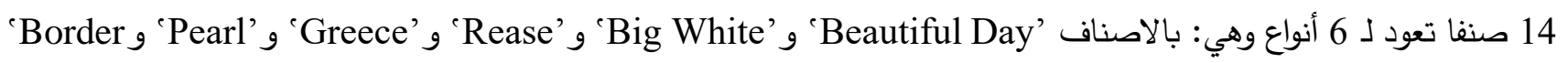

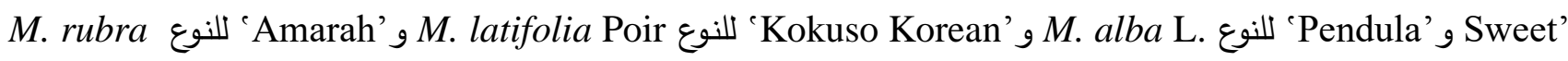

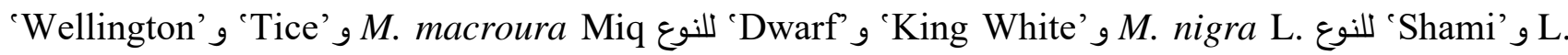


للنوع Mybrid فقد شملت الدراسة التشريحية (نصل الورقة، عرقها الوسطي، نظام التعرق فيها، فضـلا عن المكونات غير الحية

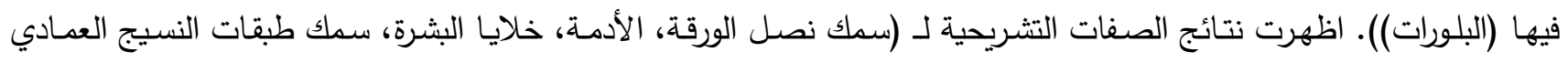

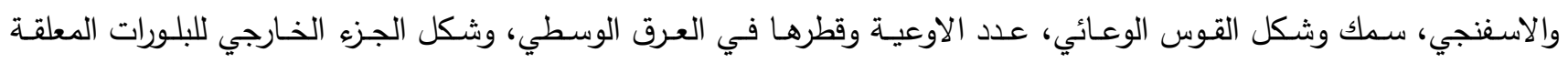

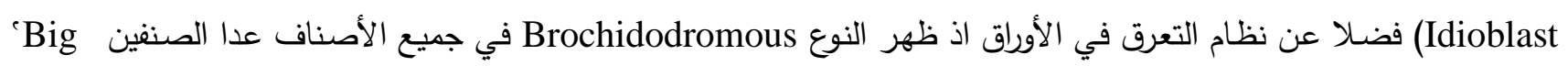

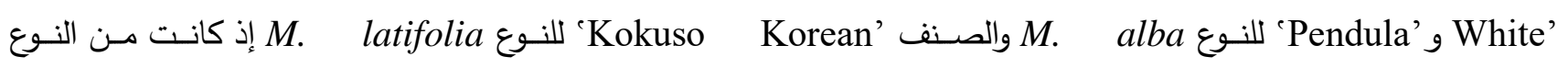
Craspedromous الكلمات المفتاحية: دراسة تشريحية، أصناف، Morus، شمال العراق.

ينتمي الجنس .Morus L الى العائلة التوتية Moraceae والتي تضم 73 جنس و1000 نوع تنتشر في المناطق الاستوائية وشبه الاستوائية وتتمو أنواع الجنس بشكل اشجار وشجيرات معمرة، أحادي او ثثائي المسكن وفي ترب مختلفة وتزهر بشكل جيد في

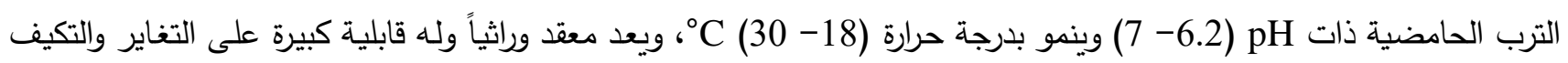
والانتشار على نطاق واسع في البيئات المختلفة [2،1،]ــ

تعد الدراسات التشريحية من الأدلة التصنيفية Taxonomic evidenes ذات الأهمية الكبيرة في تشخيص وعزل الرراتب

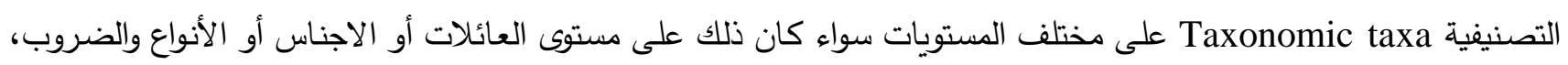
وعلى الرغم من الدراسات العديدة الأخرى التي يمكن الاعتماد عليها بجانب الصفات التشريحية ومنها المظهرية والخلويـة والكيميائية

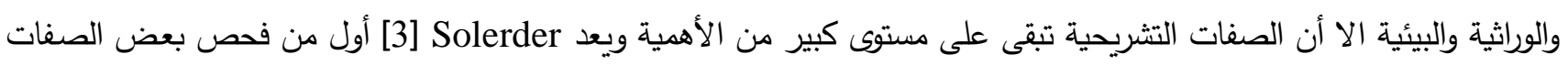
التشريحية بشكل بسيط لعائلات مختلفة من ذوات الفلقتين.

وذكر مivis و Heywood [4] أن الصفات التشريحية ذات أهمية في التشخيص Identification وفي دراسة الاتجاهات التطوريـة Phylogentic trends ودرجة العلاقة بين المراتب التصنيفية، اذ أنه بالإمكان استخدام الصفات التشريحية للورقة في دراسة الاجناس والأنواع التابعة لها.

واشار Radford وجماعته [5] أن الصفات التشريحية تدعم في كثير من الاحيان الصفات المظهرية وأنها ذات أهمية كبيرة في الدراسات التصنيفية الحديثة.

وذكر Judd وجماعته [6] أن الصفات المتعلقة بالانسجة الداخلية لـلأوراق مهـة اذ وجدت اختلافات بين خلايا النسيج

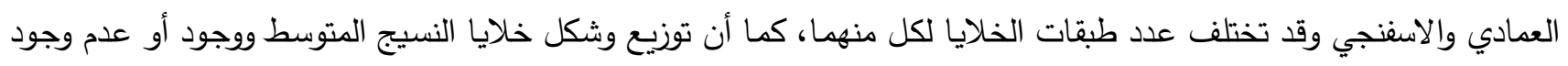

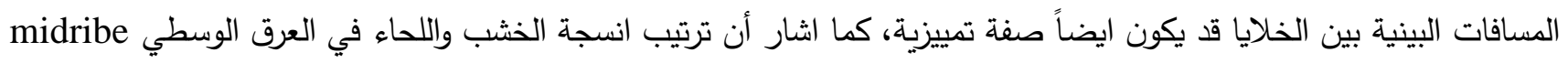
للورقة وسويقها يتم بطرق مختلفة.

أن خصـائص نسيج الورقة لها دور مهم في تصنيف الاجناس والأنواع والضـروب [8،7]. وشخص Ananda Rao

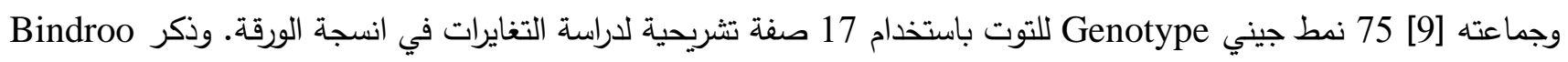

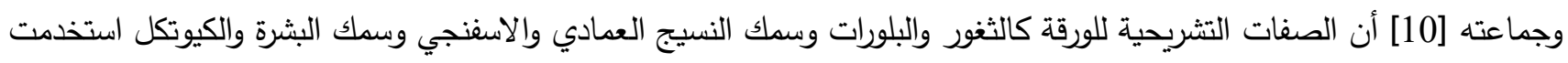
في تشخيص وتصنيف المصادر الوراثية الاصلية للتوت. كما وجد Kumar وجماعته [11] اختلافات جوهرية كبيرة بين الاصناف في الصفات التشريحية للورقة عند دراسته لـ 4 اصناف مستزرعة من التوت. إذ اعتبر Katsumata [12 شكل الجزء الخارجي ldioblast للبلورات المعلقة cystolith في أوراق 
أنواع جنس التوت صفة تثخيصية مميزة عند دراسته لـ 7 أنواع من جنس التوت. وأن اوراق العديد من العائلات للنباتات الراقية تحوي البلورات غالباً ما يتم استخدام نوعها وموقعها في تصنيف النبات [14،13]. وقد اشار

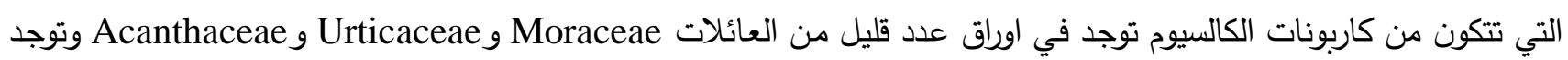
غالباً في بشرة الأوراق. واستخدم Tsutui وجماعته [16] الخرائط الكيميائية والمسح الإكتروني لتحديد مكونات البلورات في اوراق الصنف 'M.alba 'Ichinose'

إن الدراسـات الحديثة لا تخلو مـن ذكر الأهميـة التصـيفية لتعرق الأوراق Venation leaves في محاولـة لتوضـيح

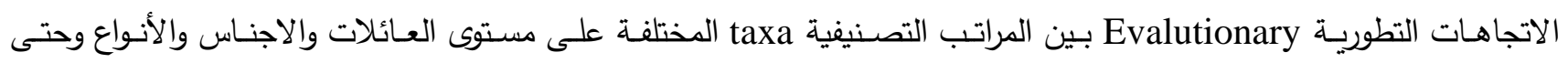
الضروب [17]

يتزايد في الآونة الاخيرة الاهتمام الكبير بزراعة اشجار التوت واستهلاك فاكهته بشكل سريع، لما لها من طعم جيد وقيمة

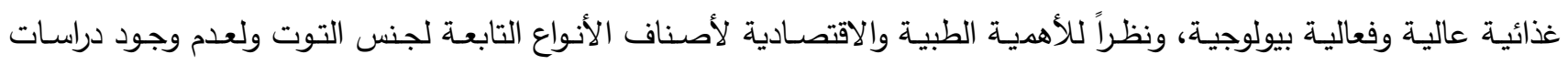
لأصناف أنواع الجنس في العراق، يهدف البحث الحالي إلى دراسة تشريحية لنصول الاوراق وعرقها الوسطي ونظام التعرق فيها

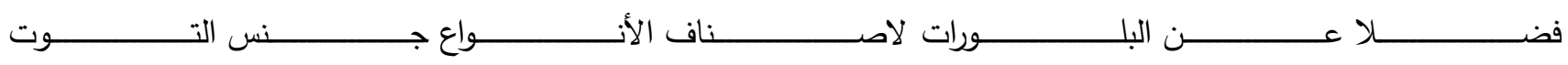
Morus L.

Materials and Methods المواد وطرائق العمل اعتمدت الدراسة على العينات الطرية التي جمعت من عدة مناطق من شمال العراق خلال السفرات الحقلية اثناء فترة النمو

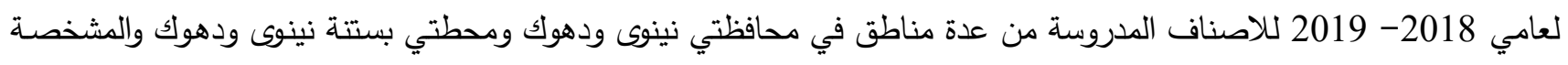
من قبل وزارة الزراعة والمستزرعة في المشاتل والحقول التابعة لها.

\section{1}

اتبعت طريقة Al-Haj [18] في تحضير شرائح دائمية للمقاطع المستعرضة لنصول الاوراق وعرقها الوسطي للاصناف قيد الدراسة بعد تثبيتها بمحلول F.A.A وغسلها ثلاث مرات بكحول اثيلي بتركيز 50\% ثم مررت بسلسلة متصاعدة من الكحول الاثيلي

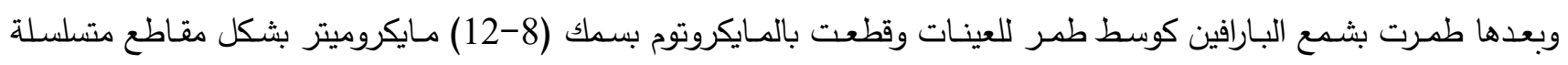
وصبغت المقاطع باستعمال صبغة السفرانين والاخضر الضوئي السريع وحملت المقاطع بعد ذلك على شرائح زجاجية باستعمال

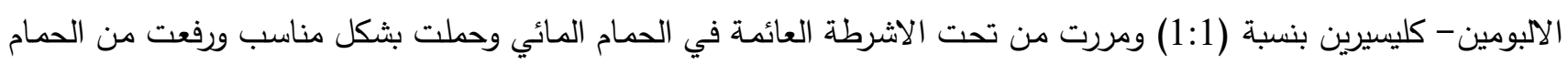

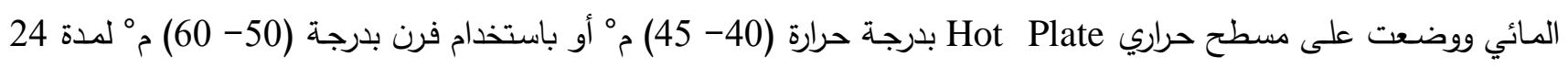

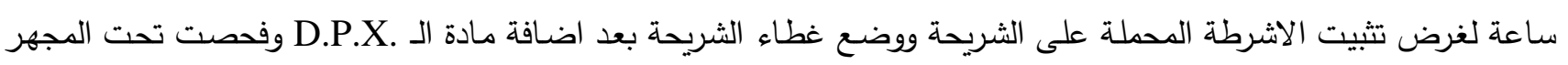
الضوئي.

\section{تعرق الاورلق Leaf Venation}

تم دراسة نظام التعرق بوضع الاوراق للاصناف قيد الدراسة في أطباق بتري حاوية على محلول هيدوكسيد الصوديوم NaoH تركيز 3\% وتركت النماذج بالمحلول لمدة (14- 20) يوم بدرجة حرارة الغرفة مع تبديل المحلول بين فترة وأخرى لإزالة النسيج المتوسط (الميزوفيل) ثم غسلت عدة مرات بالماء المقطر حسب طريقة Al-Mayyah [19] مـع بعض التحويرات لها وصورت باستخدام كاميرا رقمية دقيقة من نوع Song. 


\section{Results and Discussions النتائج والمناقشة}

$$
\text { بيانات المقاطع المستعرضة لنصل الورقة مبينة في الجدول (1و2) واللوحة (1 و2 و3 و4). }
$$

اظهرت نتائج المقاطع المستعرضة لاصناف الأنواع قيد الدراسة وجود تغايرات في سمك نصل الورقة فبلغت أعلى قيمة لها

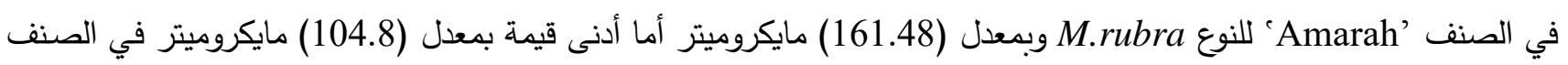

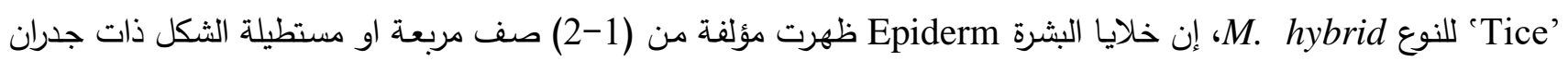

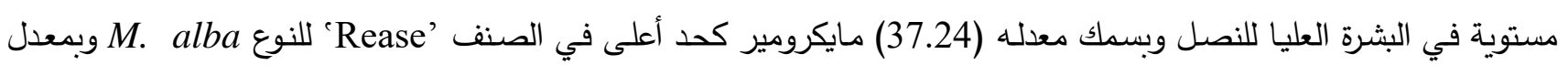

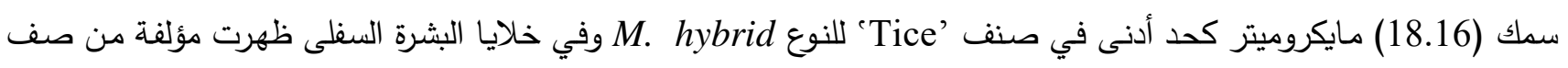

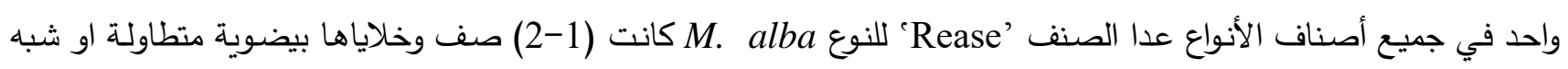
مربعة ذات جدران مستوية Straight او منحنية Curved وتباين سمكها بين اصناف الأنواع فكان أعلى قيمة لمعدلها (17.32)

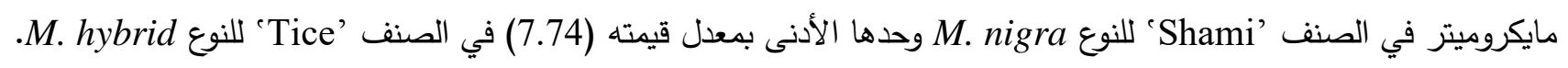
أما بالنسبة لسمك الأدمة Thickness Cuticle فوجد معدل سمكها على السطح العلوي للبشرة Adaxial الأعلى (5.44) مايكروميتر في الصنف 'Kokuso Korean' للنوع M. latifolia والادنى (3.34) مايكروميتر في الصنف 'Border Sweet' للنوع alba. alba

أما أعلى قيمة لسمك الأدمة لسطح البشرة السفلي Abaxial فكانت في الصنف 'Big White' للنوع M. alba بمعدل (3.1) مايكروميتر وأدنى قيمة سجلت في الصنف 'Rease' للنوع M. alba بمعدل 2 مايكروميتر وتدرجت بقية أصناف الأنواع

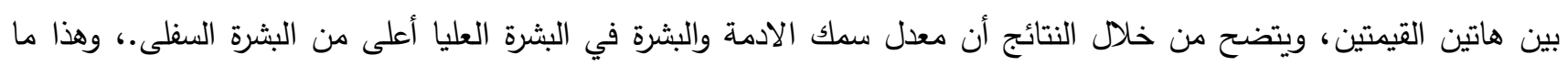
ذكره Anaada Rao وجماعته [9].

أما النظام النسيجي الاساس لجميع أصناف أنواع الجنس قيد الدراسة تتمثل بنسيج متوسط Mesophyll tissue ثنائي الوجه مؤلف من نسيج عمادي Pifacial

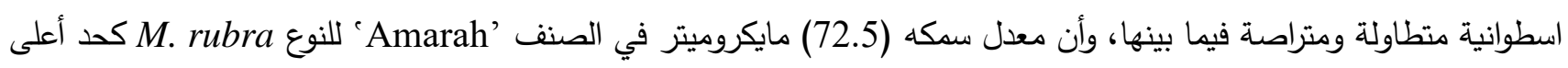
و (36.70) مايكروميتر في الصنف 'Shami' للنوع Migra كحد أدنى وتدرجت بقية الاصناف ما بين (36.80 - 63.

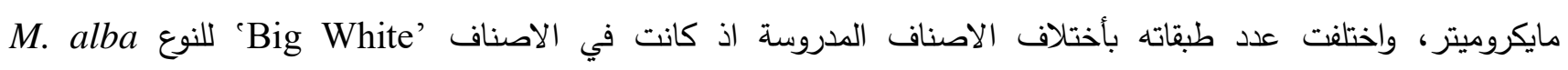

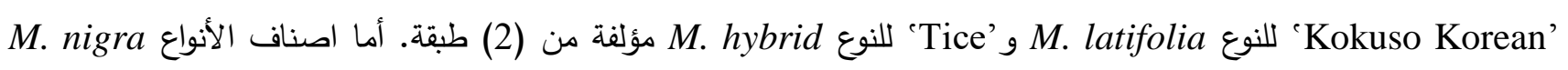

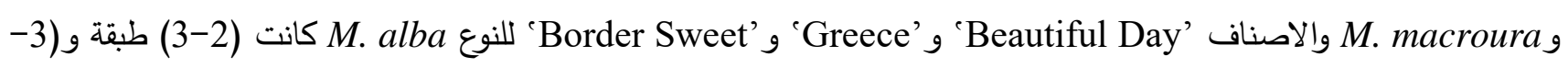

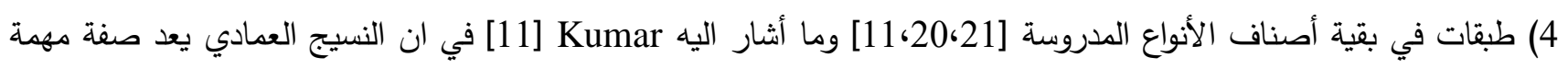
لأوراق أي نبات يعكس قدرة النمط الوراثي على التقاط الطاقة الثمسية وتقدير كفاءة عملية البناء الضوئي.

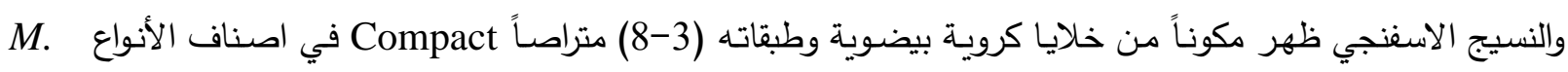

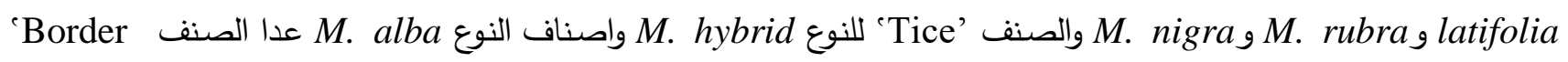

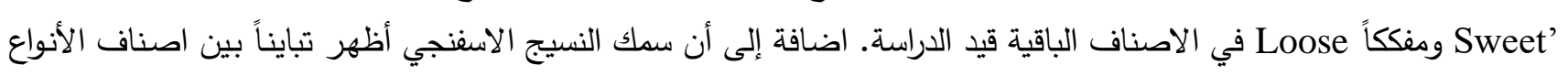

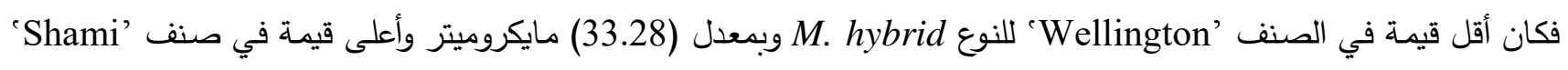

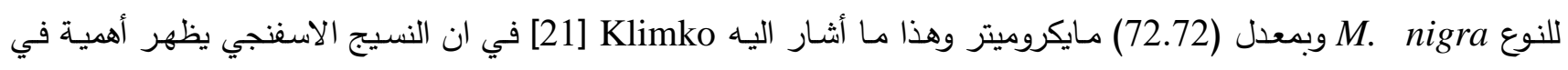
تثخيص الأنواع التابعة للعائلة التوتية Moraceae. 
أما نسبة النسيج العمادي/ النسيج الاسفنجي فقد أظهرت تغايرات والتي أمكن تقسيمها إلى مجموعتين:

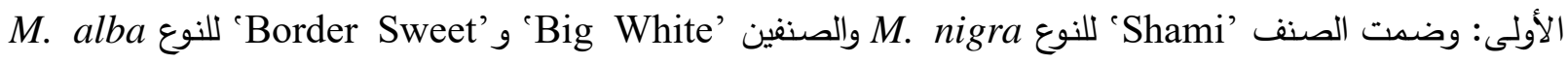
والتي كان فيها النسيج العمادي أقل سمكاً من النسيج الاسفنجي وتراوحت النسبة بينهما (0.50 - 0.79). والثانية: امتازت بأن سمك النسيج العمادي أكبر من النسيج الاسفنجي اذ كانت النسبة بين (1.02 - 1.58) وشملت بقية اصناف الأنواع قيد الدراسة. وقد أشار Kumar وجماعته [11] أن صفة نسبة النسيج العمادي/ الاسفنجي في التوت مؤشر مهم للنسيج المتوسط الذي يرتبط تركيبه مع اداء البناء الضوئي للأوراق عن طريق تتظيم الضوء الداخلي وثنائي أوكسيد الكاربون.

واتضـح من خلال المقاطع المستعرضـة للعرق الوسطي Midrib أنه محاط بنسيج بشرة مؤلف من صف واحد من الخلايا

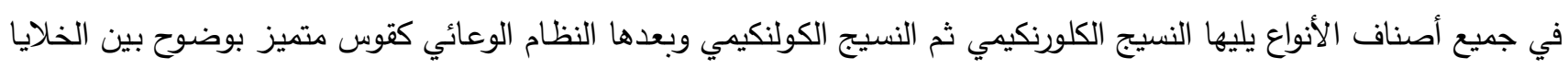

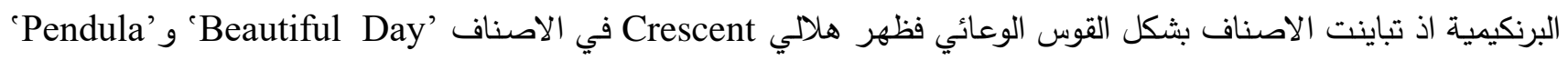

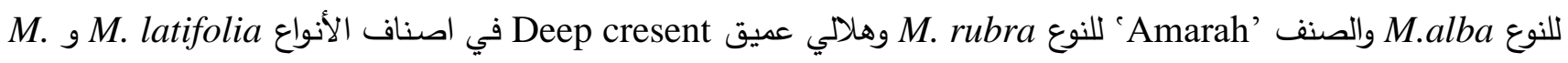

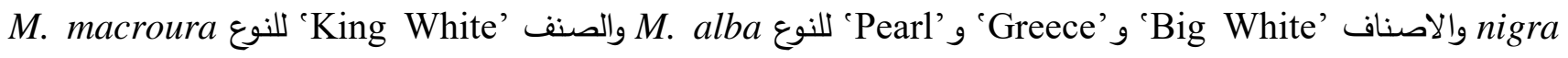

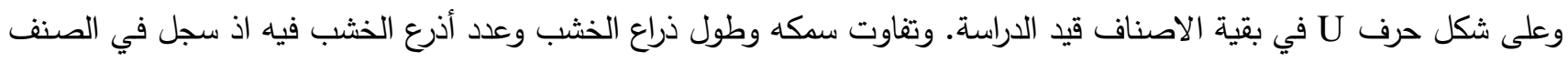

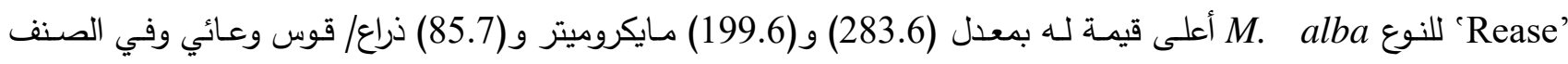
(للنوع M. alba 'Pendula'

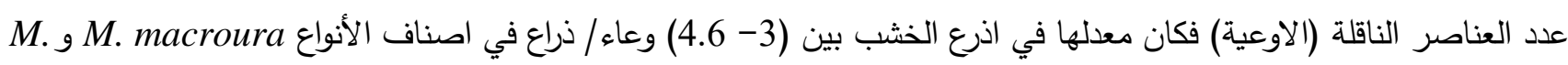

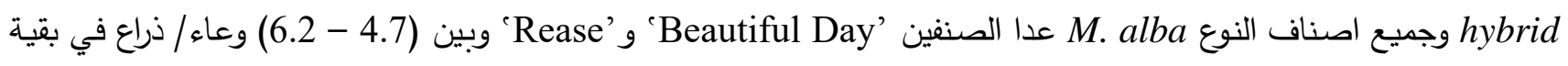
الاصناف للأنواع قيد الدراسة.

واختلفت اقطار الأوعية الناقلة بين اصناف الأنواع وضمن النوع الواحد استتاداً إلى قطر الوعاء فكان صغيراً وبمعدل (18.8

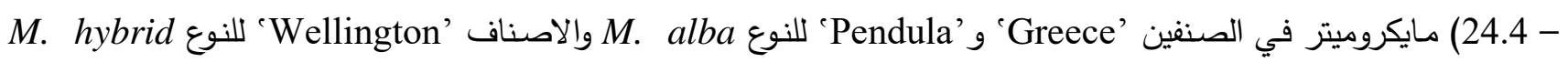

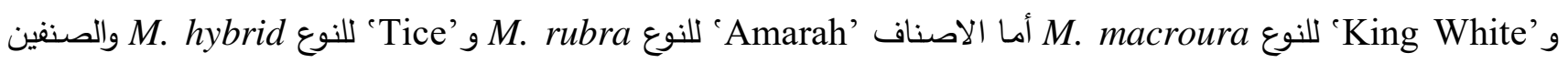

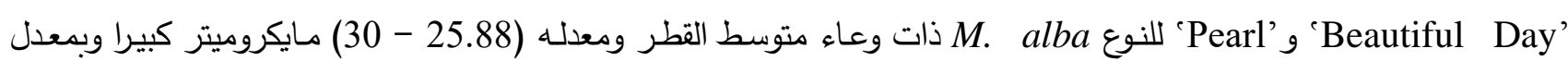
(30.4 - 35.4) مايكروميتر في بقية اصناف الأنواع للجنس قيد الدراسة.

مما تقدم اتضحت أهمية صفات المقطع المستعرض للورقة كصفة مهمة في عزل أصناف الأنواع ودعمها للصفات المظهرية والتي أشار اليها Al-Samurai [22] في أن الخصائص التشريحية للورقة لها أهمية لأنها تسهم في حل المشكلات التصنيفية وتدل على الروابط التطورية والعلاقات الوراثية بين المرتب التصنيفية. 
جدول (1) التغاير في الصفات الكمية للمقطع المستعرض لنصل الورقة لأصناف أنواع الجنس .Morus L قيد الدراسة مقاسة بالمايكروميتر

\begin{tabular}{|c|c|c|c|c|c|c|c|c|c|c|c|c|}
\hline |النماديج & 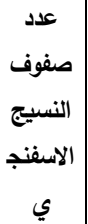 & سمك النسيج الاسفنجي & | لعفوف & سمك النسيج العمادي & سمك البشرة السفلى & سمك البشرة العليا & سمك الادمة السفلى & سمك الادمة العليا & سمك النصل & \multicolumn{2}{|l|}{ الصنف } & النوع النوع \\
\hline 1.07 & $7-4$ & $\begin{array}{l}* 51.08(68-36) \\
\quad * * 11.08\end{array}$ & $3-2$ & $\begin{array}{c}* 54.48(72-36.8) \\
* * 10.53\end{array}$ & $\begin{array}{c}* 10.44(13.2-8) \\
* * 1.86\end{array}$ & $\begin{array}{c}* 21.88(25.2-16) \\
* * 2.82\end{array}$ & $\begin{array}{c}* 2.24(2.8-1.6) \\
* * 0.34\end{array}$ & $\begin{array}{c}* 3.48(4.4-2.8) \\
* * 0.46\end{array}$ & $\begin{array}{c}* 146.2(170-124) \\
* * 17.00\end{array}$ & 'Beautiful Day' & 1 & \multirow{7}{*}{ M. alba } \\
\hline 0.77 & $8-4$ & $\begin{array}{l}* 53.2(68-44) \\
\quad * * 7.55\end{array}$ & 2 & $\begin{array}{c}* 41.2(52-32) \\
* * 5.20\end{array}$ & $\begin{array}{c}* 14.56(20-12) \\
* * 2.57 \\
\end{array}$ & $\begin{array}{l}* 33.08(40-20) \\
* * 6.49 \\
\end{array}$ & $\begin{array}{l}* 3.14(4-2.4) \\
\quad * * 0.61\end{array}$ & $\begin{array}{l}* 4.80(5.6-3.6) \\
* * 0.72\end{array}$ & $\begin{array}{c}* 149.96(180-136) \\
* * 13.24 \\
\end{array}$ & 'Big White' & 2 & \\
\hline 1.31 & $7-4$ & $\begin{array}{c}* 39.56(48-32) \\
* * 4.83 \\
\end{array}$ & $4-3$ & $\begin{array}{c}* 51.96(56-46.8) \\
* * 7.18 \\
\end{array}$ & $\begin{array}{l}* 8.84(12-7.2) \\
* * 1.68 \\
\end{array}$ & $\begin{array}{c}* 37.24(46-28) \\
* * 5.81 \\
\end{array}$ & $\begin{array}{l}* 2(2.8-1.6) \\
* * 0.50\end{array}$ & $\begin{array}{c}* 4.04(5.2-3.2) \\
* * 0.70 \\
\end{array}$ & $\begin{array}{c}* 146.56(160.8-132) \\
* * 12.52 \\
\end{array}$ & 'Rease' & 3 & \\
\hline 1.08 & $4-3$ & $\begin{array}{l}* 37.68(48-28) \\
* * 6.68\end{array}$ & $3-2$ & $\begin{array}{c}* 40.88(52-34.8) \\
* * 6.18\end{array}$ & $\begin{array}{l}* 8.12(10-6.4) \\
* * 1.32\end{array}$ & $\begin{array}{l}* 25.28(32-20) \\
* * 4.12\end{array}$ & $\begin{array}{l}* 2.76(3.6-2) \\
* * 0.55\end{array}$ & $\begin{array}{c}* 3.84(4.4-3.2) \\
* * 0.38\end{array}$ & $\begin{array}{c}* 118.04(128-110) \\
* * 6.296\end{array}$ & 'Greece' & 4 & \\
\hline 1.40 & $5-4$ & $\begin{array}{c}* 47.28(55.2-38) \\
* * 5.86 \\
\end{array}$ & $4-3$ & $\begin{array}{c}* 63.32(72-43.2) \\
* * 8.95 \\
\end{array}$ & $\begin{array}{c}* 9.28(11.2-7.6) \\
1.45 \\
\end{array}$ & $\begin{array}{c}* 24.04(32.8-16) \\
* * 5.6 \\
\end{array}$ & $\begin{array}{c}* 2.64(3.6-2) \\
* * 0.47 \\
\end{array}$ & $\begin{array}{l}* 3.64(4.4-2.8) \\
* * 0.51 \\
\end{array}$ & $\begin{array}{c}* 150.84(164-132.8) \\
* * 9.96 \\
\end{array}$ & 'Pearl' & 5 & \\
\hline 0.79 & $6-4$ & $\begin{array}{c}* 46.36(67.6-36) \\
* * 8.76\end{array}$ & $3-2$ & $\begin{array}{c}* 36.80(44-28) \\
* * 7.22\end{array}$ & $\begin{array}{l}* 8.08(12-5.6) \\
\quad * * 2.36\end{array}$ & $\begin{array}{c}* 23.84(28-16) \\
* * 4.02\end{array}$ & $\begin{array}{c}* 2.36(2.8-1.6) \\
* * 0.35\end{array}$ & $\begin{array}{c}* 3.34(4-2.6) \\
* * 0.64\end{array}$ & $\begin{array}{c}* 120.96(140-108) \\
* * 13.84\end{array}$ & 'Border Sweet' & 6 & \\
\hline 1.43 & $5-2$ & $\begin{array}{c}* 33.36(40-28) \\
* * 3.58 \\
\end{array}$ & $4-3$ & $\begin{array}{l}* 47.72(56-40) \\
* * 4.44 \\
\end{array}$ & $\begin{array}{l}* 8.16(10-6) \\
* * 1.79\end{array}$ & $\begin{array}{l}* 22.84(36-16) \\
* * 8.19\end{array}$ & $\begin{array}{c}* 2.16(2.8-1.6) \\
* * 0.68\end{array}$ & $\begin{array}{l}* 4.08(4.8-3.2) \\
* * 0.59\end{array}$ & $\begin{array}{c}* 115.6(128-106) \\
* * 7.44\end{array}$ & 'Pendula' & 7 & \\
\hline 1.03 & $5-3$ & $\begin{array}{l}* 43(52-32) \\
\quad * * 5.90\end{array}$ & 2 & $\begin{array}{c}* 44.2(61.2-35.2) \\
* * 7.19\end{array}$ & $\begin{array}{c}* 10.04(12.2-8) \\
* * 1.79\end{array}$ & $\begin{array}{l}* 28.88(40-24) \\
\quad * * 5.31\end{array}$ & $\begin{array}{l}* 2.68(3.6-2) \\
* * 0.62\end{array}$ & $\begin{array}{l}* 5.44(8.4-3.6) \\
* * 1.59\end{array}$ & $\begin{array}{c}* 134.3(144.4-117.6) \\
* * 7.64\end{array}$ & 'Kokuso Korean' & 8 & M.latifolia \\
\hline 1.52 & $7-4$ & $\begin{array}{l}* 47.8(64-36) \\
\quad * * 9.10 \\
\end{array}$ & $4-3$ & $\begin{array}{c}* 72.5(96-58.8) \\
* * 10.32\end{array}$ & $\begin{array}{l}* 9.18(12-8) \\
\quad * * 1.3\end{array}$ & $\begin{array}{l}* 25.8(28-20) \\
* * 3.05\end{array}$ & $\begin{array}{l}* 2.52(3.1-2) \\
* * 0.45\end{array}$ & $\begin{array}{l}* 4.06(4.8-3.2) \\
\quad * * 0.611\end{array}$ & $\begin{array}{c}* 161.48(180-146.8) \\
* * 9.61\end{array}$ & 'Amarah' & 9 & M.rubra \\
\hline 0.50 & $8-6$ & $\begin{array}{c}* 72.72(80-64) \\
* * 6.27 \\
\end{array}$ & $3-2$ & $\begin{array}{c}* 50.84(56-40) \\
* * 4.97 \\
\end{array}$ & $\begin{array}{c}* 17.32(21.6-12) \\
* * 2.84 \\
\end{array}$ & $\begin{array}{c}* 18.44(24-13.2) \\
* * 3.63 \\
\end{array}$ & $\begin{array}{c}* 2.38(2.8-2) \\
* * 0.33\end{array}$ & $\begin{array}{l}* 3.68(4.8-2.8) \\
* * 0.56\end{array}$ & $\begin{array}{c}* 128.7(142.8-104) \\
* * 14.72\end{array}$ & 'Shami' & 10 & M.nigra \\
\hline 1.15 & $6-5$ & $\begin{array}{l}* 44.3(52-32) \\
* * 7.08\end{array}$ & $3-2$ & $\begin{array}{c}* 48.52(61.2-38) \\
* * 7.92\end{array}$ & $\begin{array}{c}* 10.24(12.3-8) \\
* * 2.10\end{array}$ & $\begin{array}{l}* 26(36-20) \\
* * 5.32\end{array}$ & $\begin{array}{c}* 2.54(3.2-1.6) \\
* * 0.60\end{array}$ & $\begin{array}{c}* 3.79(4.8-3.2) \\
* * 0.54\end{array}$ & $\begin{array}{l}* 151.04(182-114) \\
* * 25.48\end{array}$ & 'King White' & 11 & \\
\hline 1.02 & $6-4$ & $\begin{array}{c}* 47.72(68-37.2) \\
* * 10.22 \\
\end{array}$ & $3-2$ & $\begin{array}{c}* 37.04(40-32) \\
* * 2.37 \\
\end{array}$ & $\begin{array}{c}* 11.08(16-8) \\
* * 2.37 \\
\end{array}$ & $\begin{array}{c}* 18.16(28-12) \\
* * 4.88 \\
\end{array}$ & $\begin{array}{l}* 2.74(4-1.6) \\
* * 0.67 \\
\end{array}$ & $\begin{array}{c}* 4.28(6-3.4) \\
* * 0.87 \\
\end{array}$ & $\begin{array}{c}* 104.8(123.6-90) \\
* * 11.04 \\
\end{array}$ & 'Dwarf' & 12 & M.macroura \\
\hline 1.05 & $5-4$ & $\begin{array}{l}* 35.4(44-28) \\
* * 6.66\end{array}$ & 2 & $\begin{array}{c}* 38(56-29.2) \\
* * 6.85\end{array}$ & $\begin{array}{l}* 7.74(10-4.8) \\
\quad * * 1.76\end{array}$ & $\begin{array}{c}* 22.92(28-16) \\
* * 3.41 \\
\end{array}$ & $\begin{array}{c}* 2.48(3.2-1.6) \\
* * 0.67\end{array}$ & $\begin{array}{l}* 4.02(4.8-3.6) \\
* * 0.33\end{array}$ & $\begin{array}{l}* 106(116-96) \\
* * 9.84\end{array}$ & 'Tice' & 13 & rid \\
\hline 1.14 & $6-3$ & $\begin{array}{c}* 33.28(44.8-24) \\
* * 6.14\end{array}$ & 2 & $\begin{array}{c}* 36.70(40-32) \\
* * 4.38\end{array}$ & $\begin{array}{l}* 9.72(12-8) \\
* * 1.72\end{array}$ & $\begin{array}{c}* 22.04(25.2-20) \\
* * 2.11\end{array}$ & $\begin{array}{l}* 2.72(3.2-2) \\
* * 0.45\end{array}$ & $\begin{array}{l}* 4.16(5.2-3.2) \\
* * 0.75\end{array}$ & $\begin{array}{c}* 155.8(172-142.6) \\
* * 10.64\end{array}$ & 'Wellington' & 14 & M.nyoria \\
\hline
\end{tabular}


$\frac{\text { Journal of Education and Science (ISSN 1812-125X), Vol: 29, No: 3, 2020 (178-195) }}{\mathrm{cu}}$

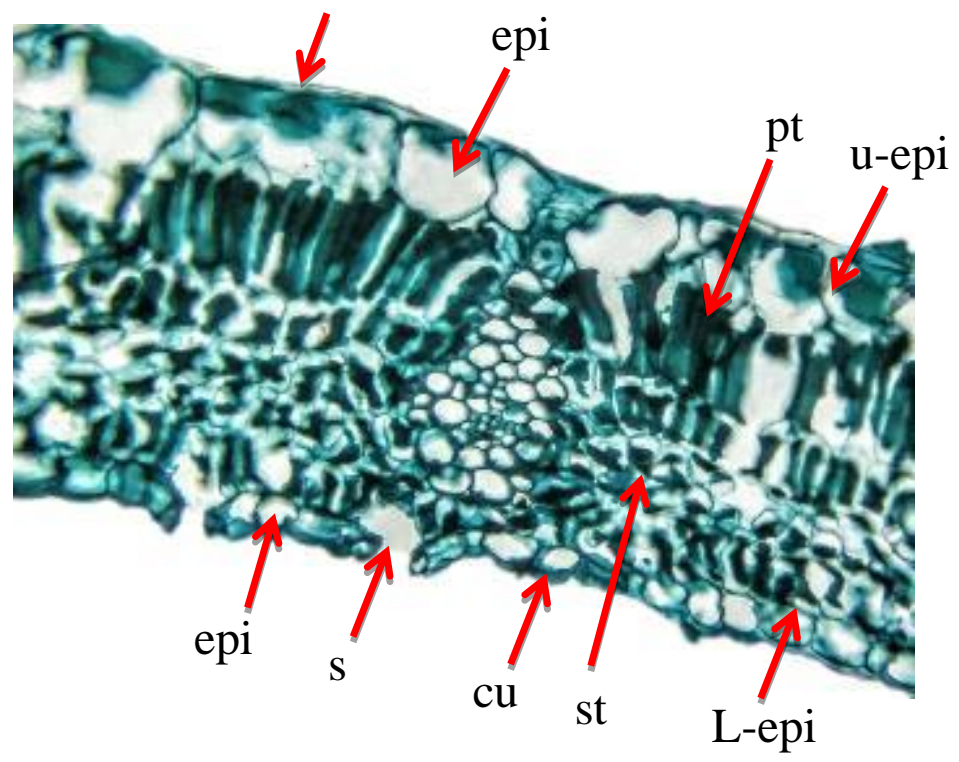

لوحة (1) مقطع مستعرض في نصل الورقة

cu-cuticle; u-epi-upper epidermis; L-epi- lower epidermis; pt-palisad tissue; st-spongy tissue; s-stomata
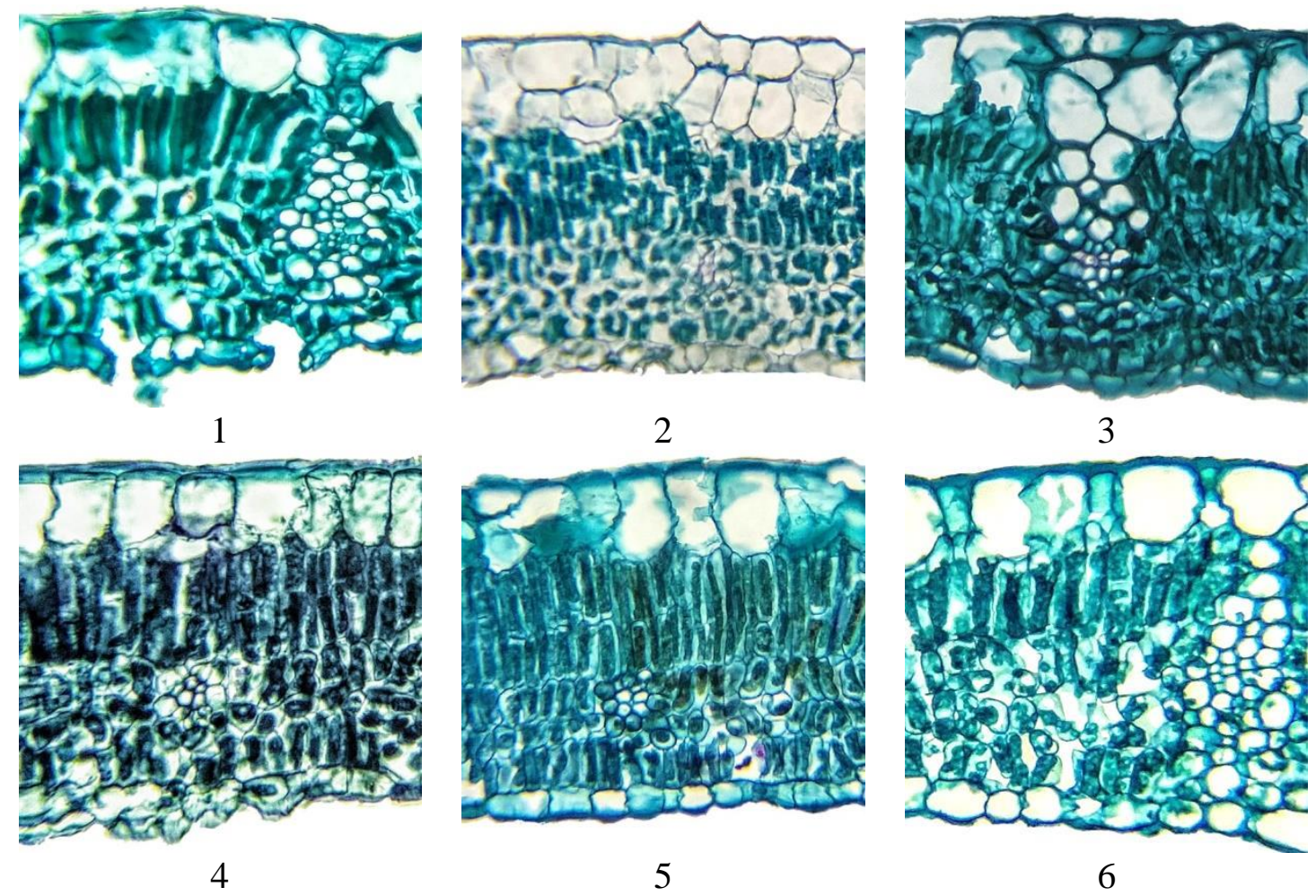


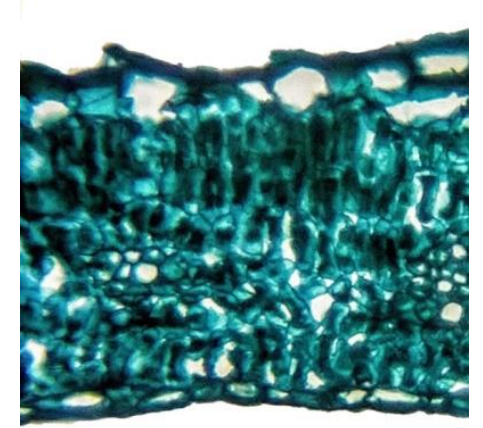

7

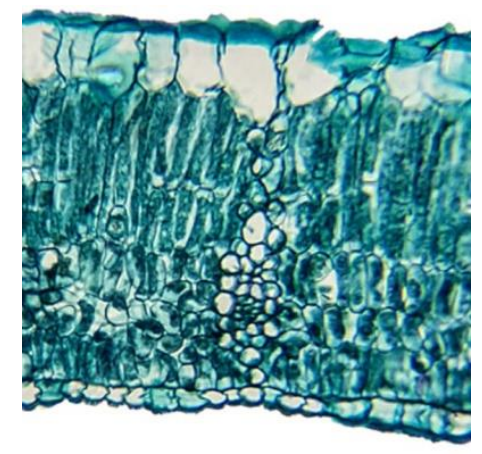

10

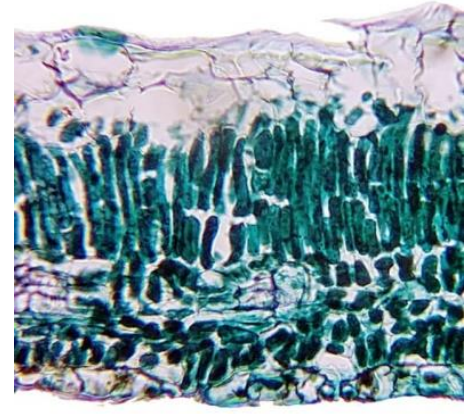

8

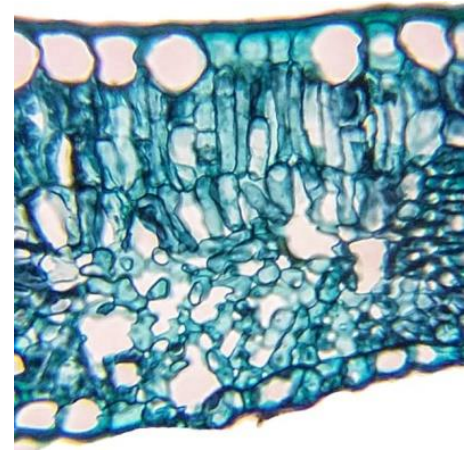

11

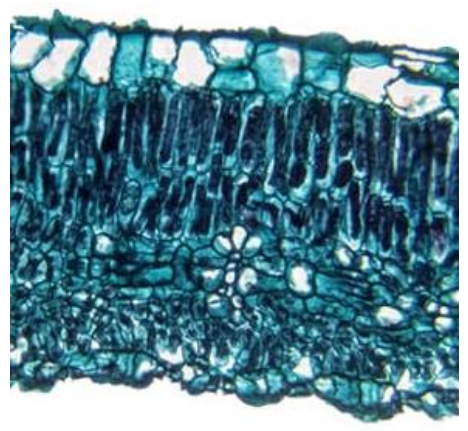

9

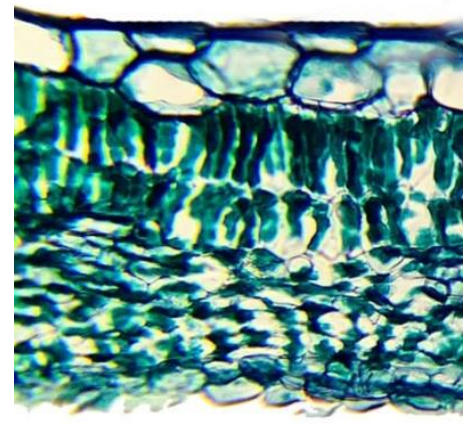

12

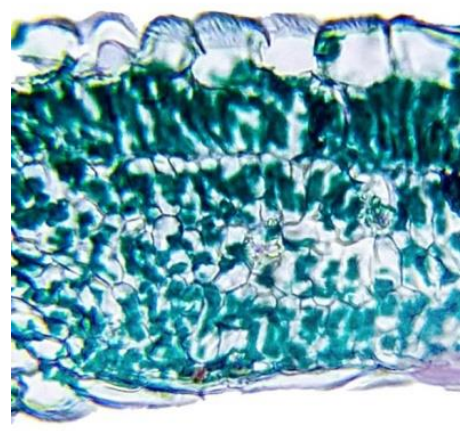

13

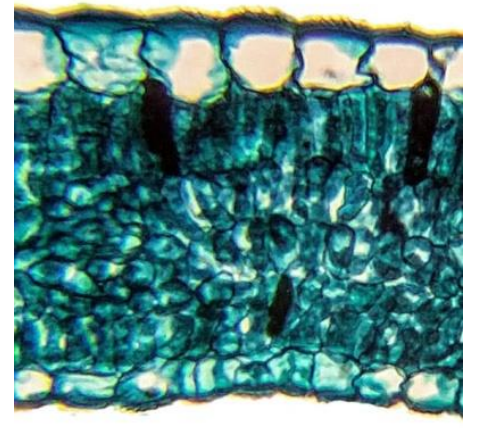

14

لوحة (2) التغاير في النسيج المتوسط في المقطع المستعرض لنصل ورقة أصناف أنواع الجنس .Morus Lيد 16X × 40X الدراسة قوة التكبير

1. M. alba 'Beautiful Day'. 2. M. alba 'Big White'. 3. M. alba 'Rease'. 4.M. alba 'Greece'. 5. M. alba 'Pearl'. 6. M. alba 'Border Sweet'. 7. M. alba 'Pendula'. 8.M. latifolia 'KokusoKoreon'. 9.M. rubra 'Amarah'. 10.M. nigra 'Shami'. 11.M. macroura 'King White'. 12.M. macroura 'Dwarf'. 13.M. hybrid 'Tice'. 14. M. hybrid 'Wellington'. 
جدول (2) التغايرات في الصفات الكمية والنوعية للمقطع المستعرض للعرق الوسطي للورقة في أصناف أنواع الجنس .Morus L قيد الدراسة (مقاسة بالمايكروميتر)

\begin{tabular}{|c|c|c|c|c|c|c|c|c|c|c|}
\hline قطر الوعاء & عدد الأوعية في & عدد اذرع الخشب & طول الذراع & سمك القوس الوعائي & الوسل العرق & | شكل القوس الوعائي | & سمك العرق الوسطي & الصنف & & النوع \\
\hline $\begin{array}{c}* 28.8(40-20) \\
* * 6.20\end{array}$ & $\begin{array}{l}* 4.7(6-3) \\
* * 0.56\end{array}$ & $\begin{array}{c}* 28.3(36-21) \\
* * 5.85\end{array}$ & $\begin{array}{l}* 135.28(156- \\
108) * * 16.72\end{array}$ & $\begin{array}{c}* 214(236-200) \\
* * 15.23\end{array}$ & 1 & Crescent & $\begin{array}{c}* 1010.4(1068-944) \\
* * 52.26\end{array}$ & 'Beautiful Day' & 1 & \multirow{7}{*}{ M. alba } \\
\hline $\begin{array}{c}* 32.2(52-12) \\
* * 13.64\end{array}$ & $\begin{array}{l}* 4.6(7-3) \\
* * 1.26\end{array}$ & $\begin{array}{c}* 36.3(45-33) \\
* * 4.51\end{array}$ & $\begin{array}{c}* 149.6(168-140) \\
* * 8.68\end{array}$ & $\begin{array}{c}* 222.2(256-196) \\
* * 17.40\end{array}$ & 1 & Deep Crescent & $\begin{array}{c}* 936.4(1000-892) \\
* * 41.46\end{array}$ & 'Big White' & 2 & \\
\hline $\begin{array}{c}* 32.2(52-16) \\
* * 12.8\end{array}$ & $\begin{array}{l}* 6.2(7-4) \\
* * 1.03\end{array}$ & $\begin{array}{c}* 85.7(93-78) \\
* * 5.72\end{array}$ & $\begin{array}{l}* 199.60(212- \\
184) * * 10.23\end{array}$ & $\begin{array}{c}* 283.6(316-248) \\
* * 22.82\end{array}$ & 1 & حرف U & $\begin{array}{c}* 1832.8(2002-1660) \\
* * 120.88\end{array}$ & 'Rease' & 3 & \\
\hline $\begin{array}{c}* 24.4(40-12) \\
* * 8.52\end{array}$ & $\begin{array}{l}* 4(5-3) \\
* * 0.67\end{array}$ & $\begin{array}{c}* 41.1(52-31) \\
* * 8.13\end{array}$ & $\begin{array}{c}* 96.8(112-80) \\
* * 10.96\end{array}$ & $\begin{array}{c}* 139.68(156.8-116) \\
* * 13.63\end{array}$ & 1 & Deep Crescent & $\begin{array}{c}* 716.4(772-580) \\
* * 63.08\end{array}$ & 'Greece' & 4 & \\
\hline $\begin{array}{c}* 25.68(36-16) \\
* * 6.02\end{array}$ & $\begin{array}{l}* 4.4(5-3) \\
* * 0.70\end{array}$ & $\begin{array}{c}* 32.8(38-23) \\
* * 6.14\end{array}$ & $\begin{array}{c}* 106.8(110-96) \\
* * 6.81\end{array}$ & $\begin{array}{c}* 195(200-172) \\
* * 9.08\end{array}$ & 1 & Deep Crescent & $\begin{array}{c}* 824(912-740) \\
* * 70.76\end{array}$ & 'Pearl' & 5 & \\
\hline $\begin{array}{c}* 30.4(44-16) \\
* * 8.88\end{array}$ & $\begin{array}{c}* 4.5(5-3) \\
* * 0.71\end{array}$ & $\begin{array}{c}* 47.2(51-45) \\
* * 1.87\end{array}$ & $\begin{array}{c}* 134(148-124) \\
* * 7.83\end{array}$ & $\begin{array}{c}* 203.4(224-188) \\
* * 9.71\end{array}$ & 1 & حرف U & $\begin{array}{c}* 1194.4(1240-1016) \\
* * 80.62\end{array}$ & 'Border Sweet' & 6 & \\
\hline $\begin{array}{c}* 18.8(28-12) \\
* * 5.26\end{array}$ & $\begin{array}{l}* 3.7(5-2) \\
* * 0.95\end{array}$ & $\begin{array}{c}* 22.2(25-18) \\
* * 2.30\end{array}$ & $\begin{array}{c}* 71.08(88-64) \\
* * 7.77\end{array}$ & $\begin{array}{c}* 120.6(148-100) \\
* * 13.89\end{array}$ & 1 & Crescent & $\begin{array}{c}* 559.6(632-504) \\
* * 44.60\end{array}$ & 'Pendula' & 7 & \\
\hline $\begin{array}{c}* 32.4(50-20) \\
* * 9.87\end{array}$ & $\begin{array}{l}* 4.7(6-3) \\
* * 0.95\end{array}$ & $\begin{array}{c}* 34.6(38-32) \\
* * 1.90\end{array}$ & $\begin{array}{c}* 152.5(180-140) \\
* * 13.16\end{array}$ & $\begin{array}{c}* 215.68(240-200) \\
* * 13.69\end{array}$ & 2 & Deep Crescent & $\begin{array}{c}* 890(980-848) \\
* * 46.72\end{array}$ & 'Kokuso Korean' & 8 & M.latifolia \\
\hline $\begin{array}{l}* 30(48-16) \\
* * 10.52\end{array}$ & $\begin{array}{c}* 5.5(7-4) \\
* * 0.85\end{array}$ & $\begin{array}{c}* 34.8(37-33) \\
* * 1.32\end{array}$ & $\begin{array}{c}* 164.8(176-148) \\
* * 7.96\end{array}$ & $\begin{array}{c}* 241.68(260-232) \\
* * 11.11\end{array}$ & 3 & Crescent & $\begin{array}{l}* 982.4(1080-920) \\
* * 50.39\end{array}$ & 'Amarah' & 9 & M.rubra \\
\hline $\begin{array}{c}* 35.4(56-20) \\
* * 11.04\end{array}$ & $\begin{array}{l}* 5.3(6-4) \\
* * 0.67\end{array}$ & $\begin{array}{c}* 41.3(48-38) \\
* * 3.09\end{array}$ & $\begin{array}{c}* 187(220-152) \\
* * 19.62\end{array}$ & $\begin{array}{c}* 250.4(304-224) \\
* * 28.17\end{array}$ & 1 & Deep Crescent & $\begin{array}{c}* 1282(1452-1180) \\
* * 109.06\end{array}$ & 'Shami' & 10 & M.nigra \\
\hline $\begin{array}{c}* 24.3(36-15.2) \\
* * 7.27\end{array}$ & $\begin{array}{l}* 3(4-2) \\
* * 0.47\end{array}$ & $\begin{array}{l}* 28(32-20) \\
* * 3.63\end{array}$ & $\begin{array}{c}* 73.4(82-60) \\
* * 7.12\end{array}$ & $\begin{array}{c}* 141(152-124) \\
* * 7.79\end{array}$ & 1 & Deep Crescent & $\begin{array}{c}* 727(800-656) \\
* * 44.40\end{array}$ & 'King White' & 11 & \multirow{2}{*}{ M.macroura } \\
\hline $\begin{array}{c}* 34(52-20) \\
* * 9.47\end{array}$ & $\begin{array}{c}* 4.1(5-3) \\
* * 0.57\end{array}$ & $\begin{array}{c}* 51.7(63-47) \\
* * 4.62\end{array}$ & $\begin{array}{c}* 139.2(156-116) \\
* * 14.58\end{array}$ & $\begin{array}{c}* 261.4(240-200) \\
* * 13.78\end{array}$ & 1 & حرف U U & $\begin{array}{c}* 1487(1576-1340) \\
* * 93.5\end{array}$ & 'Dwarf' & 12 & \\
\hline $\begin{array}{c}* 28.8(40-20) \\
* * 6.10\end{array}$ & $\begin{array}{l}* 3.5(4-3) \\
* * 0.71\end{array}$ & $\begin{array}{c}* 45.3(55-38) \\
* * 6.68\end{array}$ & $\begin{array}{c}* 100.4(112-84) \\
* * 8.04\end{array}$ & $\begin{array}{c}* 171.2(184-156) \\
* * 9.76\end{array}$ & 1 & حرف U U & $\begin{array}{c}* 1121.3(1260-1040) \\
* * 85.08\end{array}$ & 'Tice' & 13 & \multirow{2}{*}{ M.hybrid } \\
\hline $\begin{array}{l}* 24(34-12) \\
* * 7.83\end{array}$ & $\begin{array}{l}* 3.4(4-2) \\
* * 0.70\end{array}$ & $\begin{array}{c}* 38.2(41-35) \\
* * 2.35\end{array}$ & $\begin{array}{l}* 84(104-68) \\
* * 12.22\end{array}$ & $\begin{array}{c}* 145.8(160-116) \\
* * 11.87\end{array}$ & 1 & حرف U & $\begin{array}{c}* 742(820-660) \\
* * 47.82\end{array}$ & 'Wellington' & 14 & \\
\hline
\end{tabular}


Journal of Education and Science (ISSN 1812-125X), Vol: 29, No: 3, 2020 (178-195)

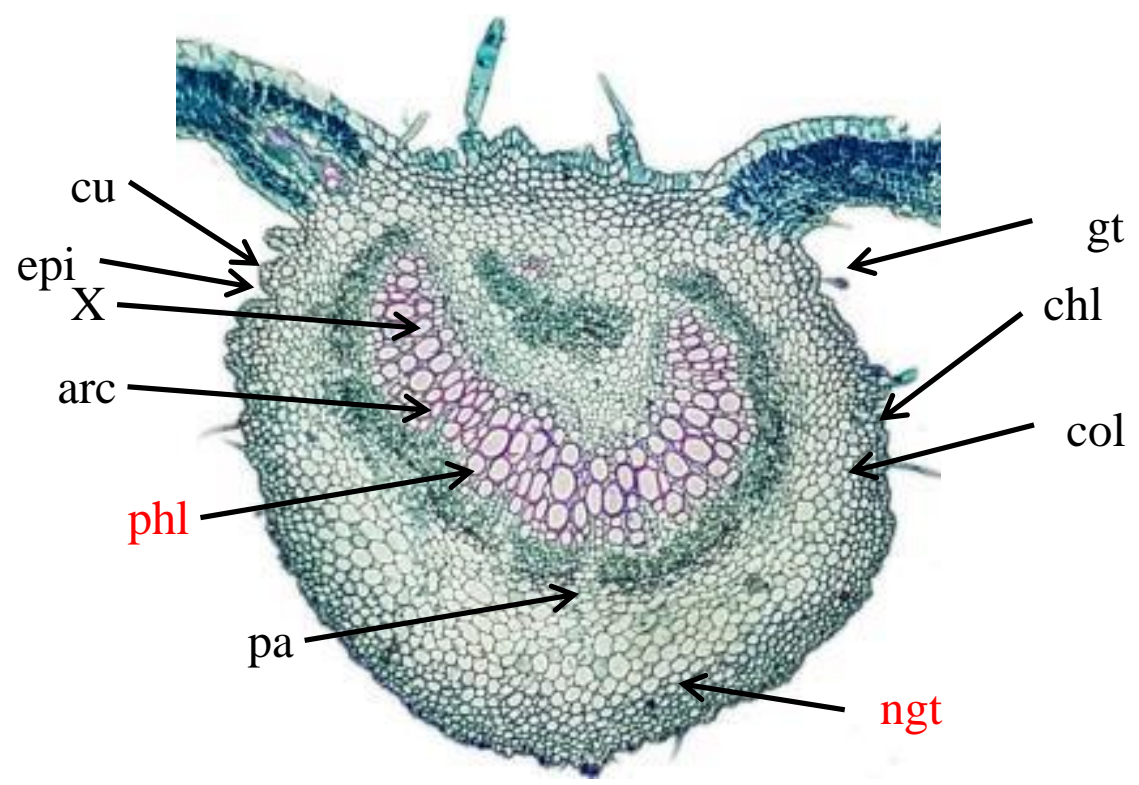

لوحة (3) مقطع مستعرض للعرق الوسطي في أورلق أصناف أنواع الجنس .Morus L قيد الدراسة قوة

$$
\text { X16 × X10 التكبير }
$$

cu-cuticle; epi-epidermis; chl-chlorenchyma; col-collenchyma; pa-parenchyma; x-xylem; ph-phloem; gt-glandular trichome; ngt; non glandular trichome

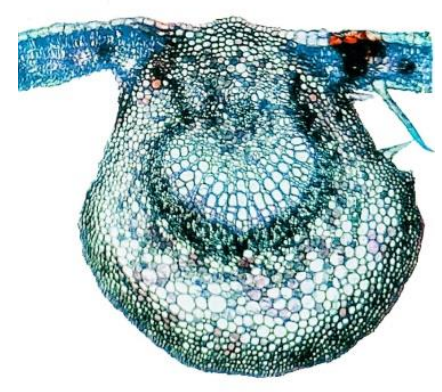

1

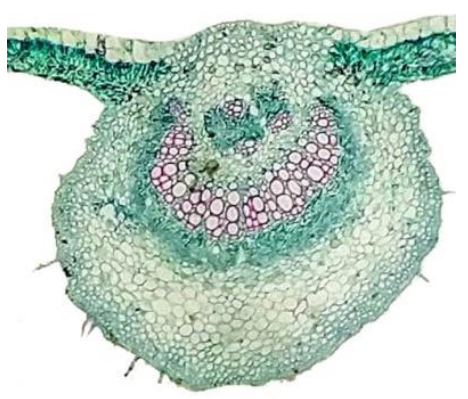

4

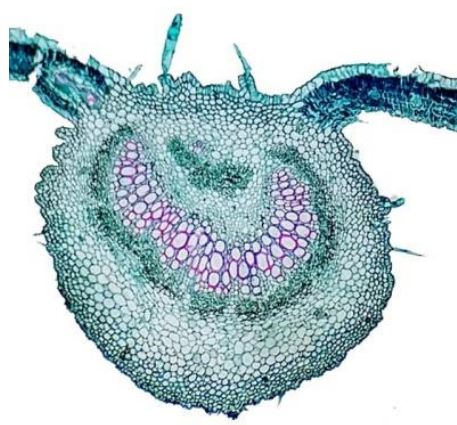

2

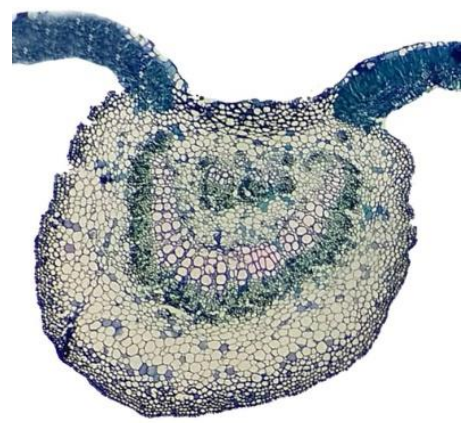

5

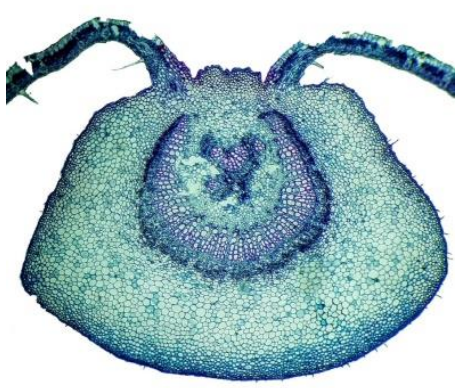

3

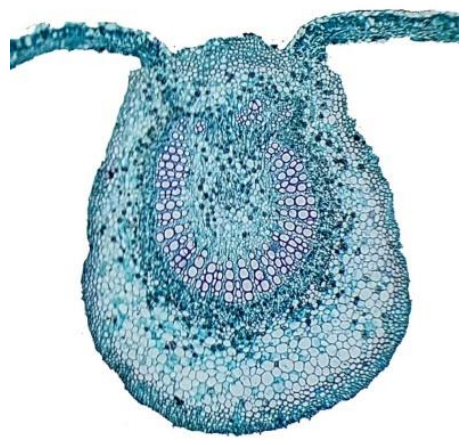

6 


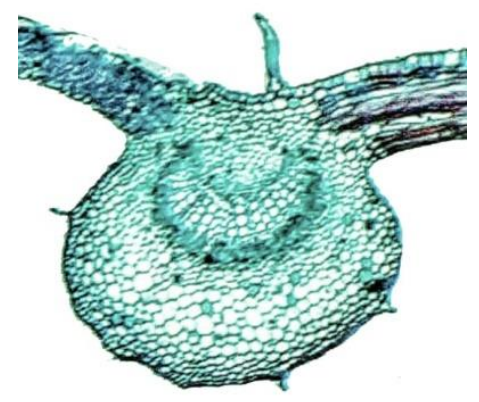

7

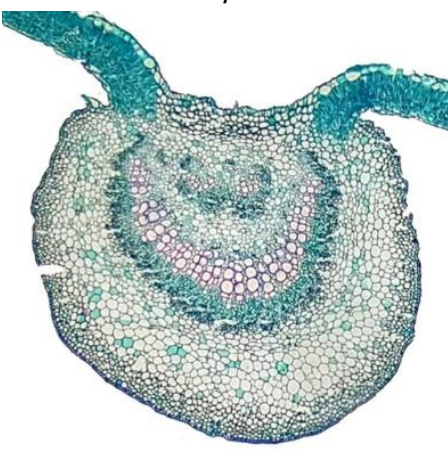

10

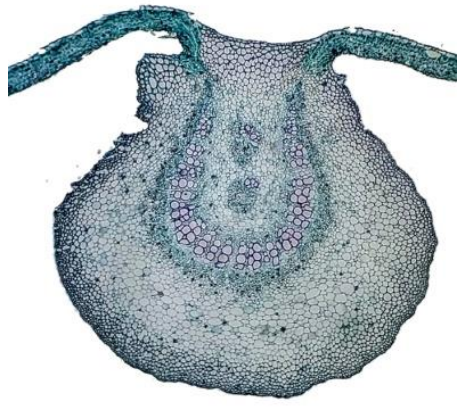

13

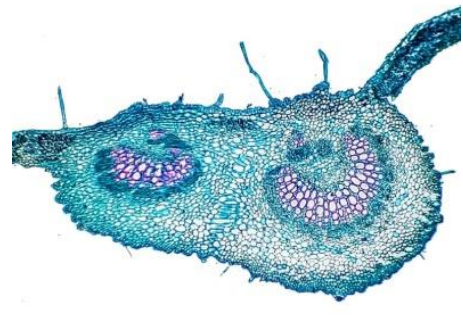

8

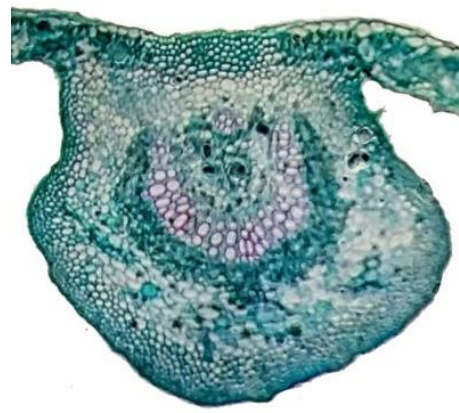

11

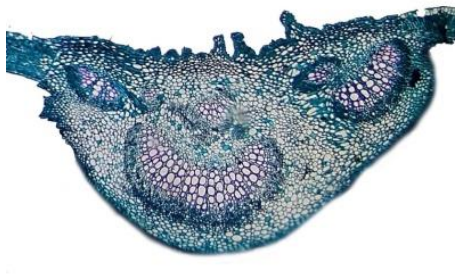

9

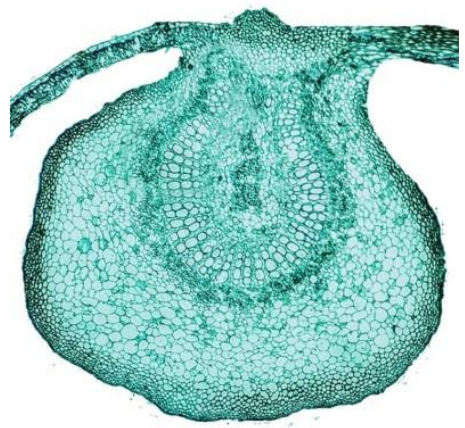

12

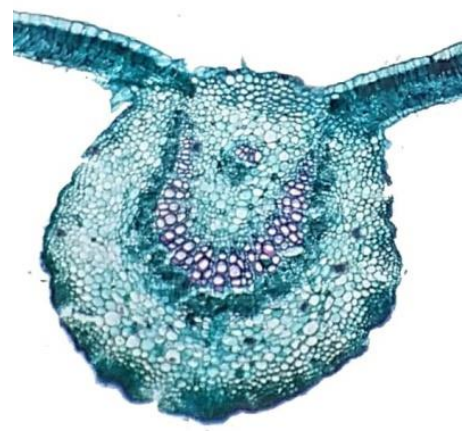

14

لوحة (4) التغايرات في شكل القوس الوعائي للعرق الوسطي في أورلق أصناف أنواع الجنس .Morus L قيد 16X × 10X الدراسة قوة التكبير

1. M. alba 'Beautiful Day'. 2. M. alba 'Big White'. 3. M. alba 'Rease'. 4.M. alba 'Greece'. 5. M. alba 'Pearl'. 6. M. alba 'Border Sweet'. 7. M. alba 'Pendula'. 8.M. latifolia 'KokusoKoreon'. 9.M. rubra 'Amarah'. 10.M. nigra 'Shami'. 11.M. macroura 'King White'. 12.M. macroura 'Dwarf'. 13.M. hybrid 'Tice'. 14. M. hybrid 'Wellington'.

كما بينت نتائج الفحص المجهري تواجد للبلورة المعلقة والتي تتكون من الجزء الخـارجي للبلورة الذي

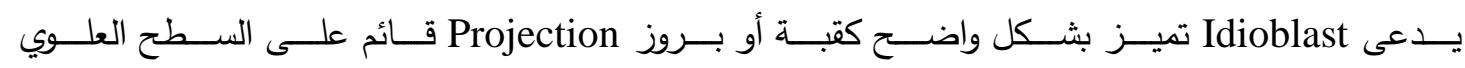
Adaxial Surface

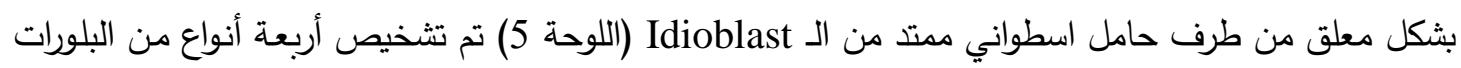

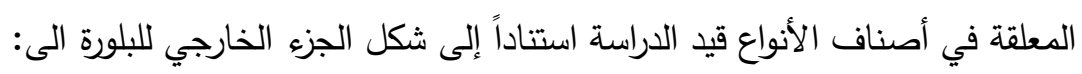

1- النوع Idioblast : البلورة على شكل قبة بدون بروز بمدى ارتفاع معدله (6.53 - 9.32) مايكروميتر • 


$$
\begin{aligned}
& \text { 2- النوع B: بروز الـ Idioblast صغير (5.47 - 9.68) مايكروميتر • } \\
& \text { 3- النوع C: بروز الـ Idioblast متوسط (16- 29.44) مايكروميتر . } \\
& \text { 4- النوع D: بروز كبير (42.8 - 45.33) مايكروميتر. } \\
& \text { وظهرت تغايرات واضحة بين أصناف الأنواع قيد الدراسـة في أنواع البلورات المعققة، كما موضـح في } \\
& \text { الجدول (3) واللوحة (6) والتي يمكن اعتمادها كصفة مهمة في تثخيص وعزل أصناف الأنواع المدروسة التي } \\
& \text { أشار اليها الباحثين [12) ول 24و 25و 26] عند دراستهم لانواع مختلفة لجنس التوت. }
\end{aligned}
$$

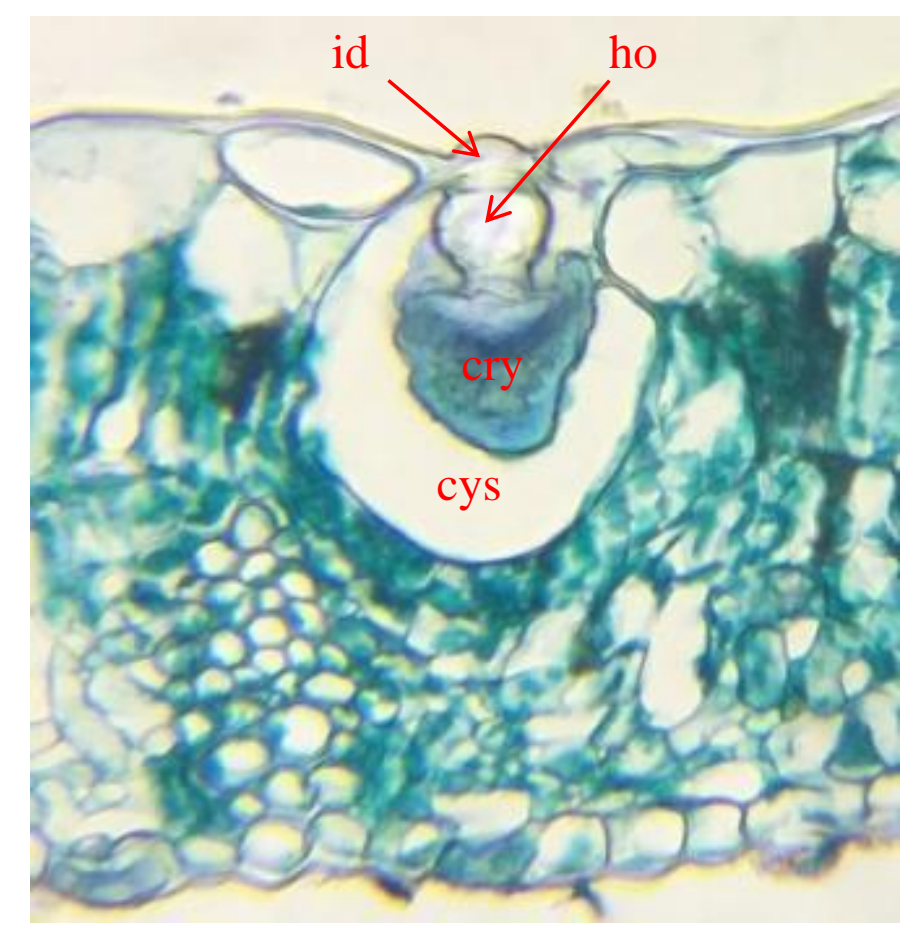

اللوحة (5) تركيب البلورة المعقة Cystolith

id: idioblast, crys: crystal, cys: cyst, ho: holder 
جدول (3) التغايرات في أنواع البلورات المعقة في أولق أصناف أنواع الجنس .Morus Lioblast الدراسة استناداً لشكل

\begin{tabular}{|c|c|c|c|c|c|c|}
\hline Type D & Type C & Type B & Type A & \multicolumn{2}{|c|}{ الصنف } & النوع \\
\hline- & - & - & + & 'Beautiful Day' & 1 & \multirow{5}{*}{ M. alba } \\
\hline- & + & - & + & 'Big White' & 2 & \\
\hline- & - & - & + & 'Greece' & 4 & \\
\hline- & - & - & + & 'Pearl' & 5 & \\
\hline- & - & - & + & 'Pendula' & 7 & \\
\hline+ & - & + & + & 'Kokuso Korean' & 8 & M.latifolia \\
\hline- & + & - & - & 'Amarah' & 9 & M.rubra \\
\hline- & - & + & - & 'Shami' & 10 & M.nigra \\
\hline- & - & - & + & 'Wellington' & 14 & M.hybrid \\
\hline
\end{tabular}




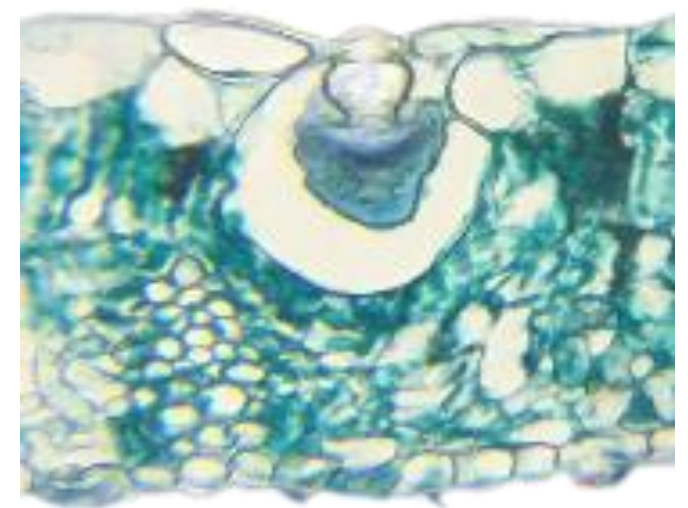

Type A

$(1,2,3,4,5,6,7,8,11,12,13,14)$

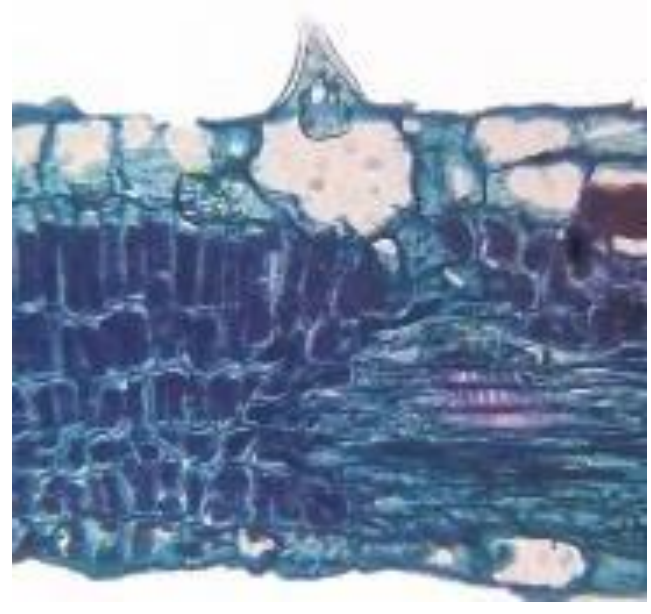

Type $\mathrm{C}$

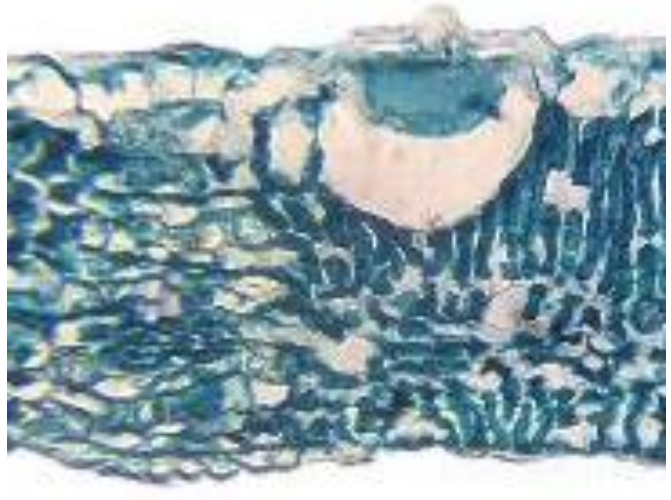

Type B

$(3,8,10)$

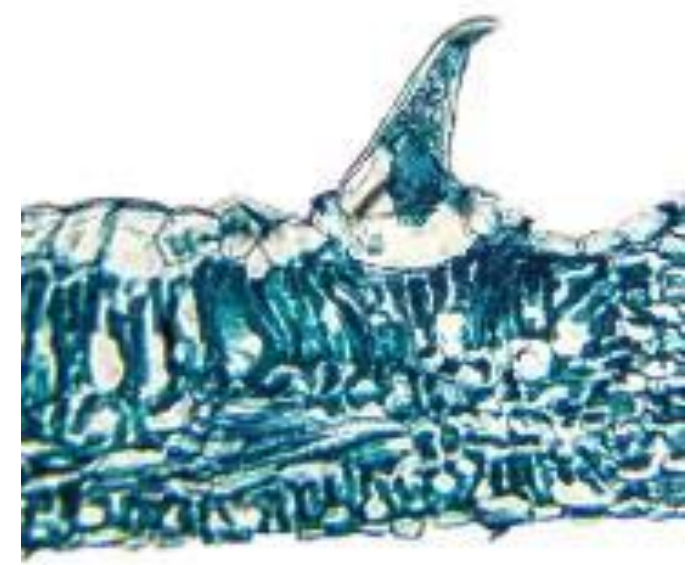

Type D

$(6,8)$

1. M. alba 'Beautiful Day'. 2. M. alba 'Big White'. 3. M. alba 'Rease'. 4.M. alba 'Greece'. 5. M. alba 'Pearl'. 6. M. alba 'Border Sweet'. 7. M. alba 'Pendula'. 8.M. latifolia 'KokusoKoreon'. 9.M. rubra 'Amarah'. 10.M. nigra 'Shami'. 11.M. macroura 'King White'. 12.M. macroura 'Dwarf'. 13.M. hybrid 'Tice'. 14. M. hybrid 'Wellington'.

$$
\begin{gathered}
\text { لوحة (6) التغاير في أنواع البلورات في أصناف أنواع الجنس .Morus L } 10 \text { 40X } \\
\text { 16X الدراسة قوة التكبير }
\end{gathered}
$$

Leaf Venation نظام التعرق في الورقة

$$
\text { التغاير في نظام تعرق الورقة موضح في اللوحة (7). }
$$

Morus L. اتسم التعرق بأنه شبكي ريشي Pinnately reticulate في أصناف الأنواع التابعة للجنس والذي تميز بوجود عرق رئيسي واحد يمتد بشكل مستقيم وتتصل العروق الثانوية معه بثكل حاد والتي كانت من

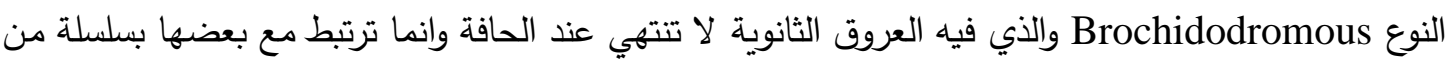

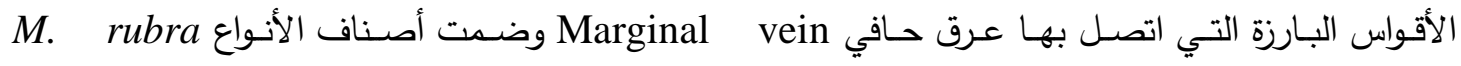




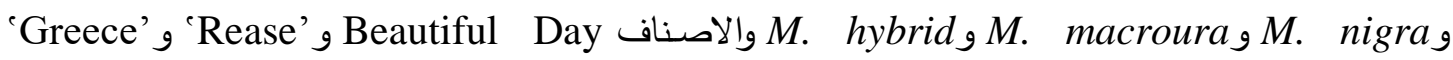

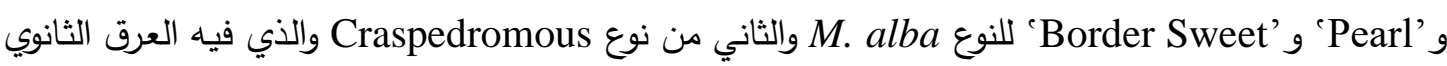

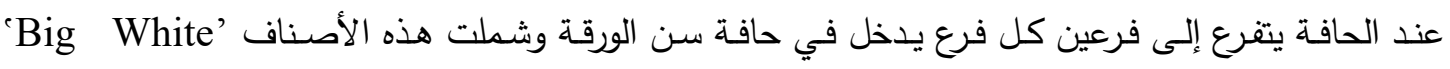

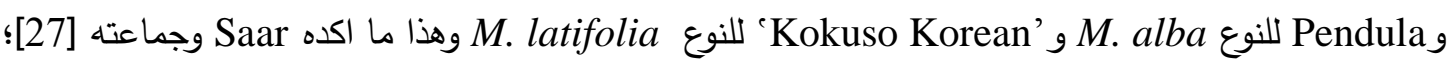
Krishna Brochidodromous

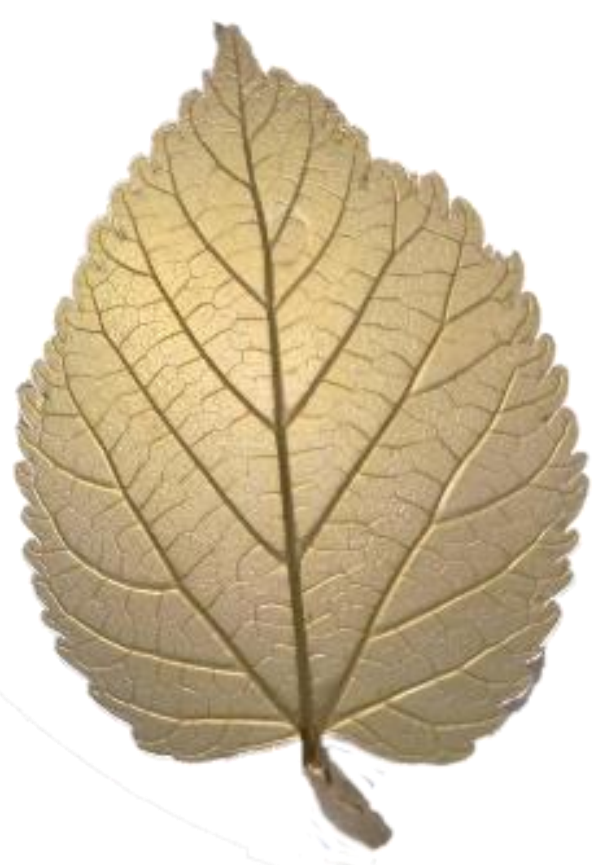

Craspedromous $(2,7,8)$

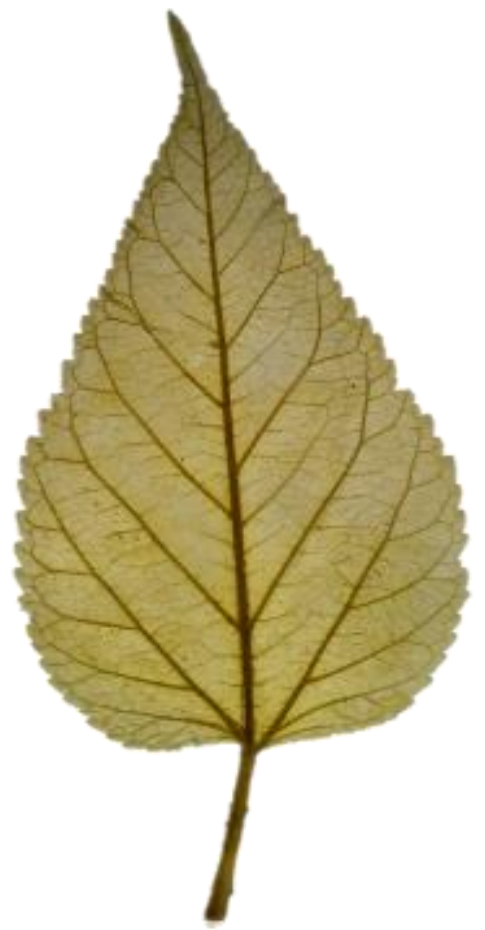

Brochidodromous $(1,3,4,5,6,9,10,11,12,13,14)$

\section{لوحة (7) التغاير في نظام تعرق الأورلق لأصناف أنواع الجنس .Morus L قيد الدراسة}

1. M. alba 'Beautiful Day'. 2. M. alba 'Big White'. 3. M. alba 'Rease'. 4.M. alba 'Greece'. 5. M. alba 'Pearl'. 6. M. alba 'Border Sweet'. 7. M. alba 'Pendula'. 8.M. latifolia 'KokusoKoreon'. 9.M. rubra 'Amarah'. 10.M. nigra 'Shami'. 11.M. macroura 'King White'. 12.M. macroura 'Dwarf'. 13.M. hybrid 'Tice'. 14. M. hybrid 'Wellington'. 
الصفات التشريحية يمكن الاستفادة منها في دعم الصفات المظهرية والكيميائية والخلويـة في تثخيص

وعزل أصناف الأنواع التابعة للجنس .Morus L.

\section{References المصادر}

[1] Kafkas, S., Ozgen, M., Dogan, Y., Ozcan, B., Ercisli, S., Serce, S. J. amer. Soc. Hort. Sci., 133(4):593-597. (2008).

[2] Wani, S. A. Ph. D. Thesis. Sher-e-Kashmir Univ. of Agric, Sci. Tech. Kashmir. (2012).

[3] Solerder, H. Vol. I. Clarendon press Oxford. p.479. (1908).

[4] Divis, P.H. and Heywood, V. H. D. van Nostrand, Princetion, New Jersey, 558pp. (1963).

[5] Radford, A. E., Dikison, W. C., Massey, J.R., Bell, C.R. Harper and Row, New York. p.891. (1974).

[6] Judd, W.S. Campbell, C.S., Kellogg, F.A., Stevens, P.F. Inc. Publishers Sunderland Massachusetts, USA. 1:464P. (1999).

[7] Scatena, VL., Giulietti, A. M., Borba, E.L., VanderBerg, C. Evol., 253:1-22. (2005).

[8] Srtgulc, K.S., Dermastia, M., Jogan, N. Bot. Helv., 116:169-178. (2006).

[9] Ananda Rao, A.A., Chauhan, S. S. Radhakrishnan, R.R., Tikader, A., Borpuari, M. M., Kamble, C.K. Journal of Biore mediation, Biodiversity and Bioavailability. 5:(1) 52-62. (2011).

[10] Bindroo, B.B., Chowdhuri, S. R., Ghosh, M.K. Journal of Crop and weed, 8(1):26-30. (2012). 
[11] Kumar, V., Kodandaramaiah, J., Rajan, M.V. Turk. J. Bot., 36:683-689. (2012).

[12] Katsumata, F. Journal of Seri cultural Science, Japan, 40(4): 312-322. (1971).

[13] Hiseh, C. F. and Huang T. C. Taiwania, 19: 19- 57. (1974).

[14] Genua, J. M. and Hillson, C. J. Ann. Bot., 56: 351- 361. (1985).

[15] Mauseth, J. D. Inc Menlo Park California p. 32- 34. (1988).

[16] Tsutui, O., Sakamoto, R., Obayashi, M., Yamakawa, S. Handa, T., NishioHamane, D., Flora, 218:44-50. (2016).

[17] Al-Mathidy, A.M. Ph.D. Dissertation. University of Mosul. College of Agricultrre. (2003). (In Arabic).

[18] Al-Haj, Hamid Ahmed University of Jordan, Amman, Jordan, p. 331. (1998). (In Arabic).

[19] Al- Mayyah, A.A. Ph. D. Thesis, Leicester Univ., U.K. (1983).

[20] Truchan, M. Wydawnictwo Naukowe Akademii Pomorskiejw Stupsku, Stupsk. (2015).

[21] Klimko, M. Steciana, 20(2):73-83. (2016).

[22] Al-Samurai, Rana Hashem Alloush PhD thesis, College of Education for Pure Sciences, Tikrit University, Iraq. (2014). (In Arabic).

[23] Sugimura, Y., Mori, T., Nitta, I., Kotani, E., Furusawa, T., Tarsumi, M., Kusakari, S.I., Wada, M., Morita, Y. Annal of Botany, 83: 543-550. (1999).

[24] Piperno, D.R. J. World Prehist., 5:155-191. (1991).

[25] Piperno, D.R. Alta Mire Press, Lanham, MD, p.238. (2006).

[26] Wallis, L. Rev. Palabot, Palynol., 125: 201- 248. (2003). 
[27] Saar, D. E., Bundy, N. C., Potts, L. J., Saar M. O. Phytologia, 94: 245- 252. (2012).

[28] Krishna, H., Singh, D., Singh, R.S.,Kumar, L., Sharma, B.D., Saroj, P.L. J. Saudi Soci. Agricult. Sci, 19(2):136-145. (2018). 